\title{
Gravimetric geoid of a part of south India and its comparison with global geopotential models and GPS-levelling data
}

\author{
$\mathrm{N}_{\text {SRINIVAS }}{ }^{1, *}, \mathrm{~V}$ M TIWARI ${ }^{1}, \mathrm{~J} \mathrm{~S} \mathrm{TARIAL}^{2}, \mathrm{~S} \mathrm{PRAJAPti}^{3}$, \\ A E Meshram ${ }^{1}$, B Singh ${ }^{1}$ and B NAGARAJAN ${ }^{2}$ \\ ${ }^{1}$ National Geophysical Research Institute (CSIR), Uppal Road, Hyderabad 500 606, India. \\ ${ }^{2}$ Indian Institute of Surveying and Mapping, Hyderabad, India. \\ ${ }^{3}$ Indian Institute of Geomagnetism, Navi Mumbai, India. \\ *Corresponding author.e-mail: srinarakula@gmail.com
}

\begin{abstract}
Precise information of geoid undulations is essential for obtaining the orthometric heights from Global Positioning System (GPS) measurements over any region; apart from providing the information of subsurface density distribution. This paper presents computation of geoid undulations over a part of southern Indian region from terrestrial gravity and elevation data using remove-restore technique that involves spherical Fast Fourier Transform (FFT) to compute 'Stokes' coefficients. Computed geoid undulations are compared with geoid obtained from global geopotential models such as EGM2008 and EIGENGRACE02S and measured GPS-levelling records at 67 locations. Statistical analysis of comparison suggests that the computed gravimetric geoid model has a good match with the geoid determined from GPS-levelling with rms of $0.1 \mathrm{~m}$ whereas EGM2008 has $0.46 \mathrm{~m}$. The differences of GPS-levelling with EGM2008 at majority of stations fall in the range of $\pm 0.5 \mathrm{~m}$, which indicates that EGM2008 may be used for orthometric height determination with an accuracy of $<0.5 \mathrm{~m}$ in the south Indian region and offers a reasonably good transformation platform from ellipsoid to local datum. However, local determination of geoid is necessary for better accuracy of orthometric height from GPS. The gravimetric geoid calculated from the available gravity data shows considerable improvement to the global model and can be used to achieve orthometric height with an accuracy of $0.1 \mathrm{~m}$.
\end{abstract}

\section{Introduction}

In recent years, improved accuracy of geodetic measurements from satellites have made it possible to determine precise ellipsoidal coordinates; latitude, longitude and height above the ellipsoid using global positioning systems (GPS). Ellipsoidal heights are heights above a reference ellipsoid, e.g., WGS84 and the conversion of ellipsoidal height into the orthometric height or height above the geoid requires a correspondingly accurate knowledge of the geoid undulation $(\mathrm{N})$. The knowledge of geoid undulation can be used to infer the subsurface mass distribution of the earth, in addition to the engineering applications of surveying. The recent gravity models, e.g., EGM2008, provide a global variation of geoid undulations though with less accuracy. Geoid heights over local area is obtained by subtracting the orthometric height (levelling) from ellipsoidal height (GPS) through the GPSlevelling observations or calculated from terrestrial gravity values due to the lack of spatial

Keywords. Gravimetric geoid; EGM2008; south India; EIGEN-GRACE02S; GPS. 
resolutions and accuracy of global models. Determination of geoid undulations over southern Indian region is of specific importance because the largest geoid depression in the world is centered to the south of India encompassing southern India (Marsh 1979) and therefore a large spatial gradient of geoid undulation is observed in this region. The geoid height decreases from central Indian region to south; reaching up to minimum value of $-106 \mathrm{~m}$ located in the Indian Ocean.

Numerous global geopotential coefficient models are available, which primarily present the long wavelength information about the geoid and the geopotential. There are hybrid models as well. For example, EGM2008 that uses long wavelength data from satellite and short wavelength data from available terrestrial gravity. These models provide fairly good information over the region of small geoidal anomalies or when substantial terrestrial data from a region are used in developing the model. But, the regions which have large geoidal anomalies (i.e., south India) and enough terrestrial data are not included (i.e., from India) in the development models; it is necessary to compare these models with computed geoid from the local gravity data. This work presents the computation of high resolution gravimetric geoid using spherical FFT over a part of south India region and compares GPS-levelling data, satellite geopotential model - EIGEN-GRACE02S and EGM2008 with local gravimetric geoid. This exercise is a first attempt to compute the geoid undulations concurrently using gravity data and GPS-levelling observations and compare them with geoid undulations obtained from global geopotential models over southern part of India.

\section{Data}

GPS measurements in campaign mode were carried out at 44 first order levelling Bench Marks (BM) to determine the ellipsoidal height. All the observation points are connected by a closed GPS traverse circuit starting from the known station and closed at the other known station to check the consistency and accuracy of observation points. GPS observations in static mode are recorded for about 3 hours at each location using Trimble 5700 dual frequency GPS receivers. The GPS data are processed using Trimble Geomatic Office software with $95 \%$ confidence limits using Hyderabad and Bangalore IGS stations as reference (Tarial 2010). The observation points of the project area were connected in

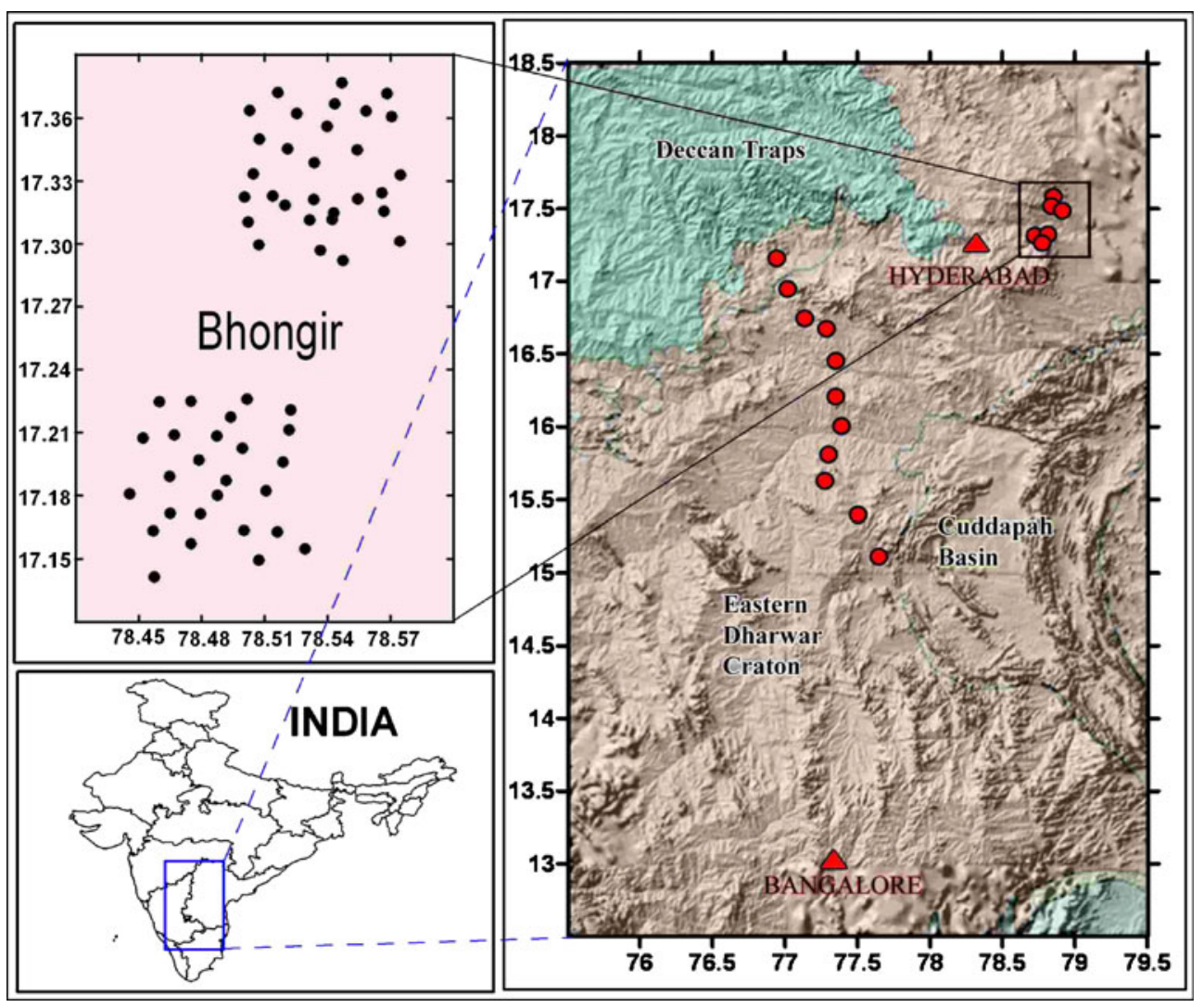

Figure 1. Location of Digital Terrain Model over study area (latitude $\left(12^{\circ} .5^{\prime} \leq \phi \leq 18^{\circ} .5^{\prime}\right)$ and longitude $\left(75^{\circ} .5^{\prime} \leq \lambda \leq\right.$ $\left.79^{\circ} .5^{\prime}\right)$ showing coordinates of GPS locations with known first order benchmarks (levelling). 
a closed levelling loop that run between known high precision benchmarks established by G\&RB Survey of India. Spirit levelling network in the area is determined with respect to the mean sea-level datum of India with an accuracy of few millimeters as per survey done for Geodetic Datum Transformations (GDT). Difference of ellipsoidal height determined from GPS measurements and orthometric height from precise levelling provides the geoidal undulation $N_{\text {GPS }}$ (De lacy et al. 2001). In addition to this data, $N_{\mathrm{GPS}}$ along a base line of $\sim 200 \mathrm{~km}$ consisting of 21 observation points at geodetic BMs are also determined using the procedure mentioned above. Observation locations are plotted in figure 1. Free-air anomaly values of the area are taken from Gravity Anomaly Map of India (GMSI 2006), which is based on data at $\sim 5 \mathrm{~km}$ grid spacing (figure 2). The accuracy of free-air anomalies obtained from map (GMSI 2006) is of order of 0.5-1 mGal. However, accuracy of gravity observations carried out over 56 well distributed stations in two blocks of $15^{\prime} \times 30^{\prime}$, situated north and south of Bhongir region, is likely to be less than $0.2 \mathrm{mGal}$.

\section{Method}

A high precision gravimetrically determined geoid is often computed using the remove-restore

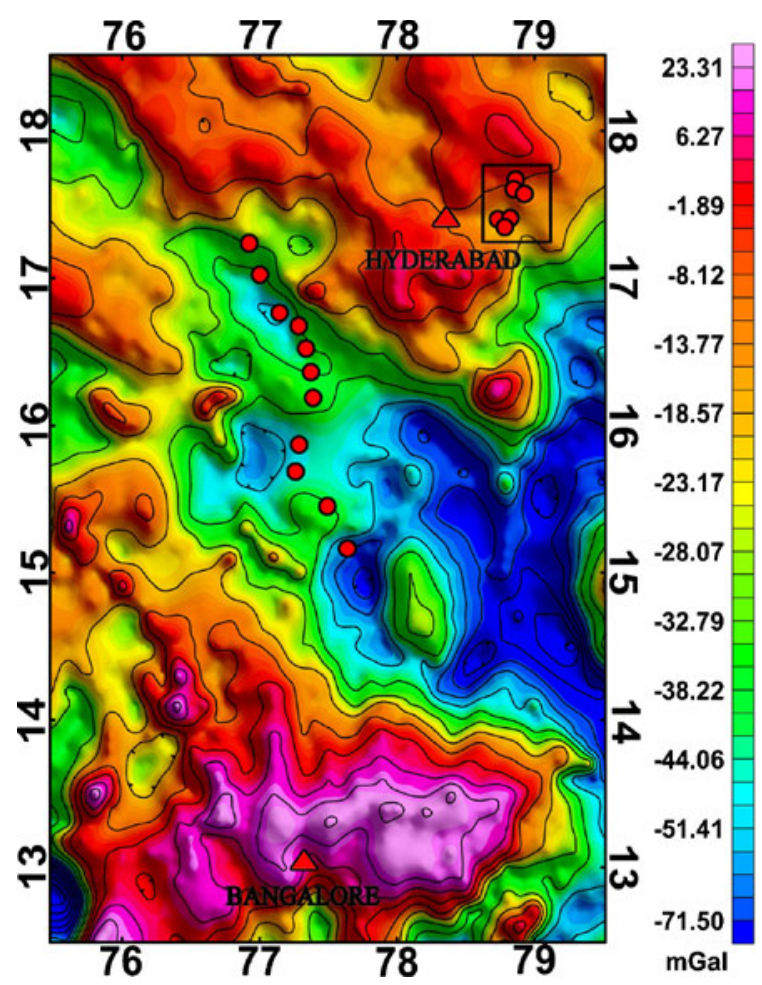

Figure 2. Free-air anomaly map (GMSI 2006) with reference points (triangles), on which GPS-levelling measurements are made. technique, incorporating the Stokes' integral solution. Stokes' formula (Heiskanen and Moritz 1967) connects gravity anomalies to geoid heights and requires integration of the gravity field over whole earth. Thus global geopotential models (GGM) are utilized in the computation of gravimetric geoid. This method has been employed to compute the gravimetric geoid over many parts of the world (Forsberg and Tscherning 1981; Forsberg 1992; Luo and Chen 2002; Singh et al. 2007; Yilmaz et al. 2010). We followed the same procedure for computation of gravimetric geoid and compared the results from GPS-levelling measurements at selected location in the southern part of India (figure 1).

The quasi gravimetric geoid undulation $(N)$ is expressed as:

$$
N=N_{\mathrm{GGM}}+N_{\mathrm{RTM}}+\frac{R}{4 \pi \gamma} \int_{\sigma} S(\psi) \Delta g_{\mathrm{res}}
$$

where $N_{\mathrm{GGM}}$ is geoid undulation computed from GGM, which presents long wavelength contribution, $N_{\mathrm{RTM}}$ is the indirect effect of the terrain on the geoid undulation, $S(\psi)$ is Stokes' function, $\Delta g_{\text {res }}$ is residual gravity anomaly effect and $\gamma$ is mean normal gravity.

The residual gravity anomaly $\left(\Delta g_{\text {res }}\right)$ is obtained after removal of long wavelength gravity anomalies using global geopotentail model and the topographic effect from the terrestrial free-air gravity anomalies. It is mathematically expressed as:

$$
\Delta g_{\mathrm{res}}=\Delta g_{\mathrm{obs}}-\Delta g_{\mathrm{GGM}}-\Delta g_{\mathrm{RTM}}
$$

where $\Delta g_{\mathrm{obs}}$ is free-air gravity anomaly, $\Delta g_{\mathrm{GGM}}$ is the free-air gravity anomaly computed from GGM, and $\Delta g_{\mathrm{RTM}}$ is the gravity anomaly correction due to terrain.

Geoid undulations $\left(N_{\mathrm{GGM}}\right)$ and gravity anomalies $\left(\Delta g_{\mathrm{GGM}}\right)$ of GGM are calculated by sets of coefficients consisting of a series of spherical harmonic functions of corresponding global models. Indirectly, these coefficients are providing the information of long wavelength components which are involved in remove-restore approach. The $N_{\mathrm{GGM}}$ and $\Delta g_{\mathrm{GGM}}$ obtained from the global model of the gravity field (Heiskanen and Moritz 1967) are:

$$
\begin{aligned}
N_{\mathrm{GGM}}= & \frac{G M}{r \gamma} \sum_{n=2}^{n_{\max }}\left(\frac{a}{r}\right)^{n} \sum_{m=0}^{n} P_{n m}(\cos \theta) \\
& \times\left[\Delta c_{n m} \cos m \lambda+\Delta s_{n m} \sin m \lambda\right] \\
\Delta g_{\mathrm{GGM}}= & \frac{G M}{r^{2}} \sum_{n=2}^{n_{\max }}\left(\frac{a}{r}\right)^{n}(n-1) \sum_{m=0}^{n} P_{n m}(\cos \theta) \\
& \times\left[\Delta c_{n m} \cos m \lambda+\Delta s_{n m} \sin m \lambda\right]
\end{aligned}
$$


where GM is the geocentric gravitational constant referring to the total mass (earth's body plus atmosphere $),(r, \boldsymbol{\theta}, \boldsymbol{\lambda})$ are the spherical polar coordinates of the computation point (geocentric radius, colatitudes and longitude, respectively), $\gamma$ is the mean normal gravity, $\boldsymbol{a}$ is the semi major axis of the ellipsoidal earth model, $\Delta C_{n m}$ and $\Delta S_{n m}$ are the fully normalized spherical harmonics coefficient of the GGM, $P_{n m}(\cos \theta)$ are the fully normalized associated Legendre polynomials, $n$ and $m$ are the degree and order of the expansion of global geopotential model.

Gravimetric geoid is computed using GRAVSOFT software (Tscherning et al. 1992; Tscherning 2008), which is implemented by Python application for Windows/DOS both GNU-Fortran and Lahey FORTRAN compilers and consists of several modules. A flow chart of computation is presented in figure 3, which documents the procedure of computing gravimetric geoid using GRAVSOFT. The complete procedure of remove-restore technique is divided into three steps which are represented by the colour coding, i.e., remove (represents the red), compute (blue) and restore (violet) coloured circles in process respectively. Similarly, green (represents the inputs), light blue (resultant inputs are obtained from applications) and orange (final output) boxes respectively. In remove process, spherical harmonic coefficient of references GGM and free-air gravity anomalies are taken as inputs to GEOEGM application to remove the contribution of long wavelength information of the GGM from the free-air gravity anomalies (i.e., $\Delta g_{\text {obs }}-$ $\Delta g_{\text {GGM }}$ ). The contribution of topography in gravity and geoid is estimated using Digital Terrain Model (DTM) in order to compute the terrain correction and the indirect effect on the geoid. We have computed terrain effect using GTOPO30 DTM (Forsberg 1994; Sterzai et al. 2008), which has elevation grid, regularly spaced at 30-arc seconds (approximately $1 \mathrm{~km}$ ). TCGRID application is used to produce two DTMs, like coarse (CDTM) and reference (RDTM). The RDTM is obtained from the detailed DTM by simple averaging. The CDTM is used in the outer zone around each computation point. As mentioned above three DTM grids are used to reduce the local effect of the resultant gravity anomalies, which results the residual gravity anomalies $\left(\Delta \mathrm{g}_{\text {obs }}-\Delta \mathrm{g}_{\mathrm{GGM}}-\Delta \mathrm{g}_{\mathrm{RTM}}\right)$ on actual earth surface by TC application.

The empirical and local covariance functions of the gravity anomalies are required to estimate the

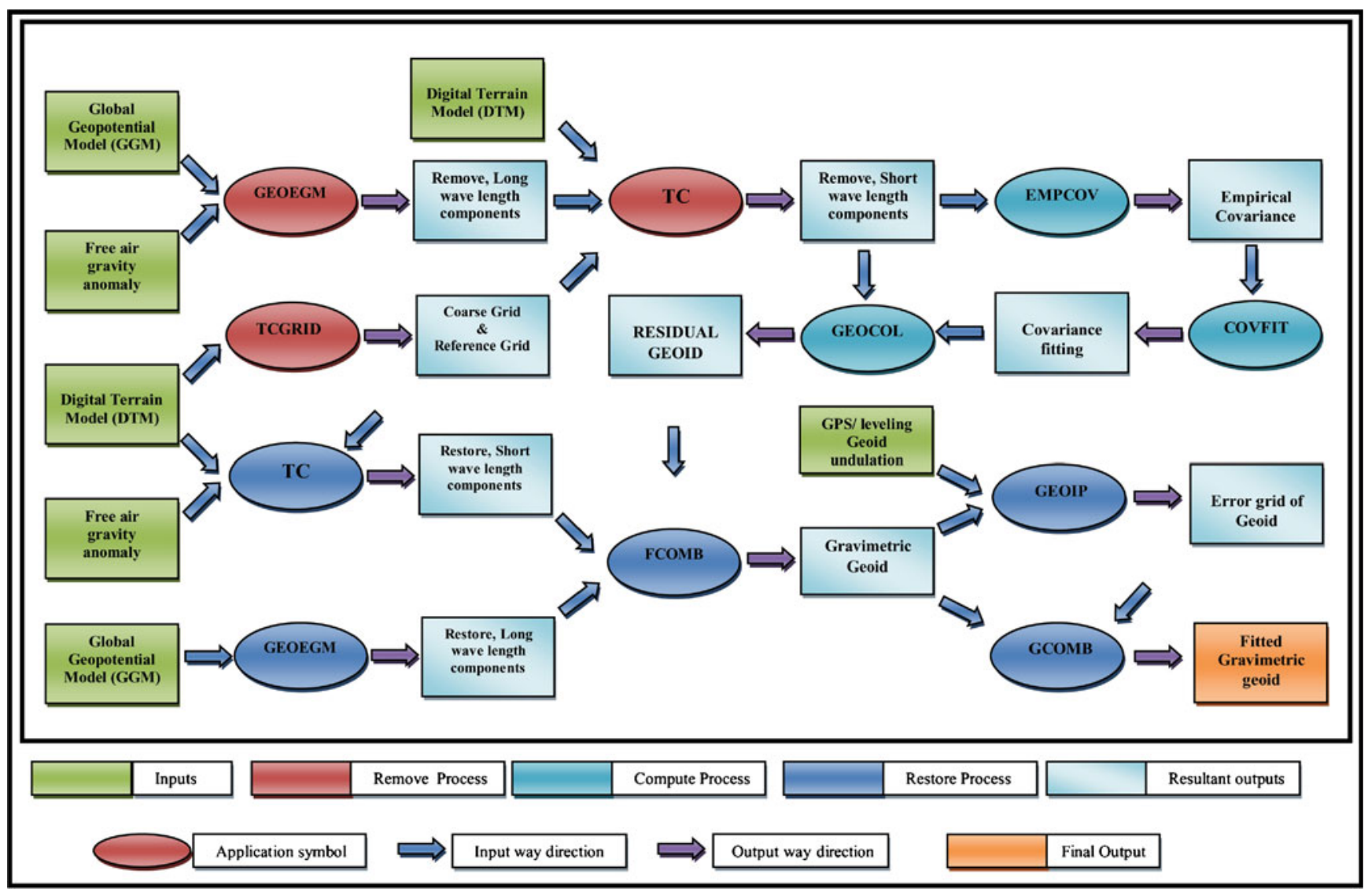

Figure 3. Flowchart of the steps of the RCR technique to compute gravimetric geoid. 
residual geoid and these functions are determined from the residual gravity anomalies to estimate the values of parameter to build the local covariance model. The actual use of covariance fitting involves a local covariance function which requires the estimation of three parameters: the depth of the sphere of Bjerhammar $\left(R_{B}=-0.702 \mathrm{~km}\right)$, the scale factor $(\mathrm{AA}=1.01)$ and the variance of the gravity anomalies at zero height $\left(\right.$ VARG $\left.=777.89 \mathrm{mgal}^{2}\right)$. Local covariance model is estimated using EMPCOV and COVFIT applications by the formula (Knudsen 1987) is:

$$
\begin{aligned}
\operatorname{COV}(P, Q)= & a \sum_{n=2}^{N_{\max }} \sigma_{n}^{2}\left(\frac{R^{2}}{r r^{1}}\right)^{n+1} P_{n}(\cos (\psi)) \\
& +\sum_{n=N_{\max }+1}^{\infty} \frac{A}{P_{n t y p e}(n)}\left(\frac{R_{B}^{2}}{r r^{1}}\right)^{n+1} \\
& \times P_{n}(\cos (\psi))
\end{aligned}
$$

where $P_{n} \cos (\psi)$ are the Legendre polynomials, $a$ and $A$ are the scale factor of the error degree variance and scale factor of the degree variance respectively, $R$ is the mean radius of the Earth, $P$ and $Q$ with radial distances $r$ and $r^{\prime}$, spherical distance $(\psi)$ and $\sigma_{n}^{2}$ is error anomaly degree variances of the reference field.
The residual gravity anomalies $\left(\Delta g_{\text {res }}\right)$ have been subsequently converted into residual geoid heights $\left(N_{\text {Res }}\right)$ by using the fast collocation method with outcome values like depth of Bjerhammar sphere $\left(R_{\mathrm{B}}\right)$, VARG and scale factor (AA) which are inputs for GEOCOL application. The gravimetric geoid $(N)$ was computed using FCOMB application, by the addition of geoid undulations with contribution of global geopotential model $\left(N_{\mathrm{GGM}}\right)$ and residual terrain effects $\left(N_{\mathrm{RTM}}\right)$ to the residual geoid undulation $\left(N_{\mathrm{RES}}\right)$. In the end, geoid heights of points are obtained by restoring the previous removed components. The result of the gravimetric geoid refers to a global reference system, i.e., global center of mass, average zero-potential surface, etc. Such a geoid may be offset by 1-2 m from the apparent geoid heights determined from GPS on the benchmarks. The reason for the difference is the assumption of zero level. Levelling zero refers to local or regional mean sea-level, which is different from the global, zero vertical datum due to the sea-surface topography. Also, error in long-wavelength geopotential models, underlying local geoid estimation, may yield offsets of up to $1 \mathrm{~m}$ or so. In the remove-restore technique, about 99\% of the geoid heights come from global model. GPS-levelling data is used to resolve the orthometric heights in local vertical datum to best fit the

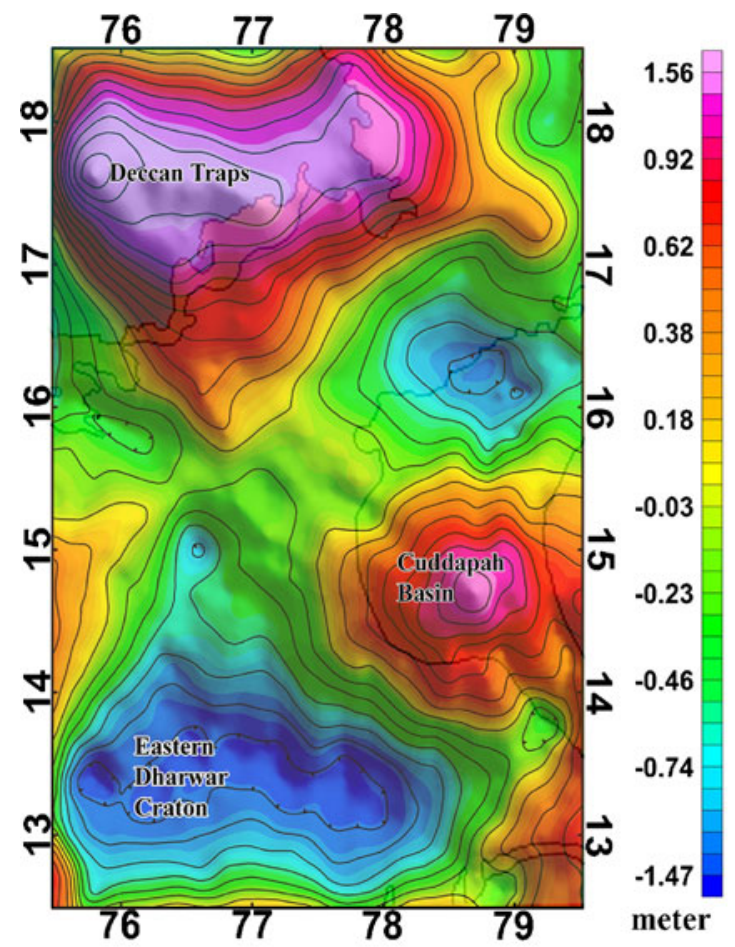

(a)

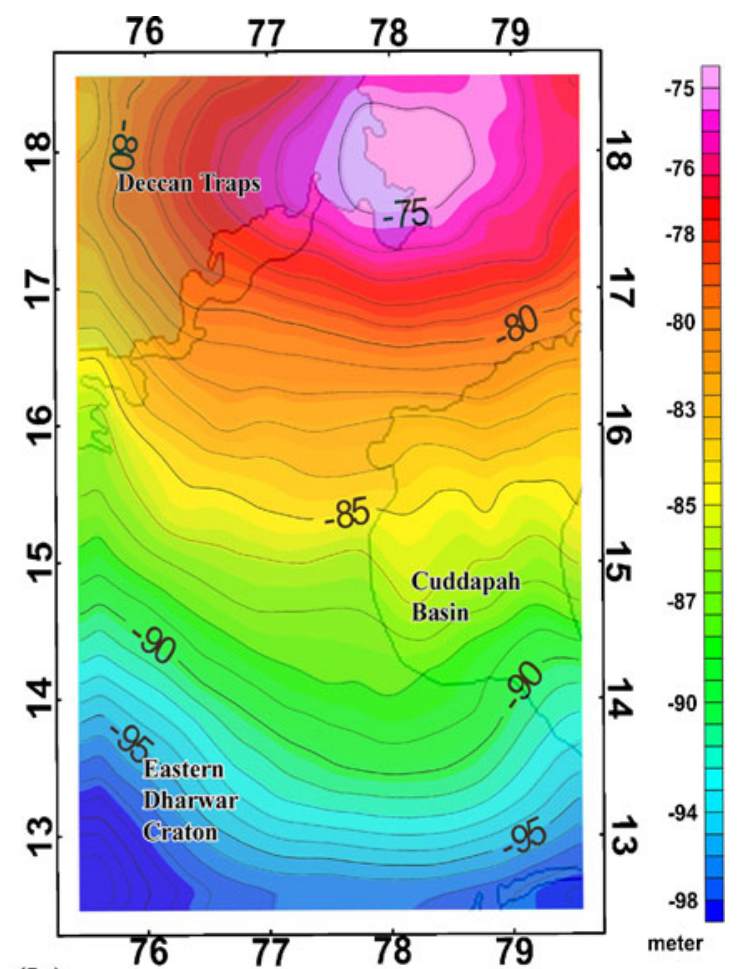

(b)

Figure 4. Plots of (a) residual geoid and (b) gravimetric geoid. 

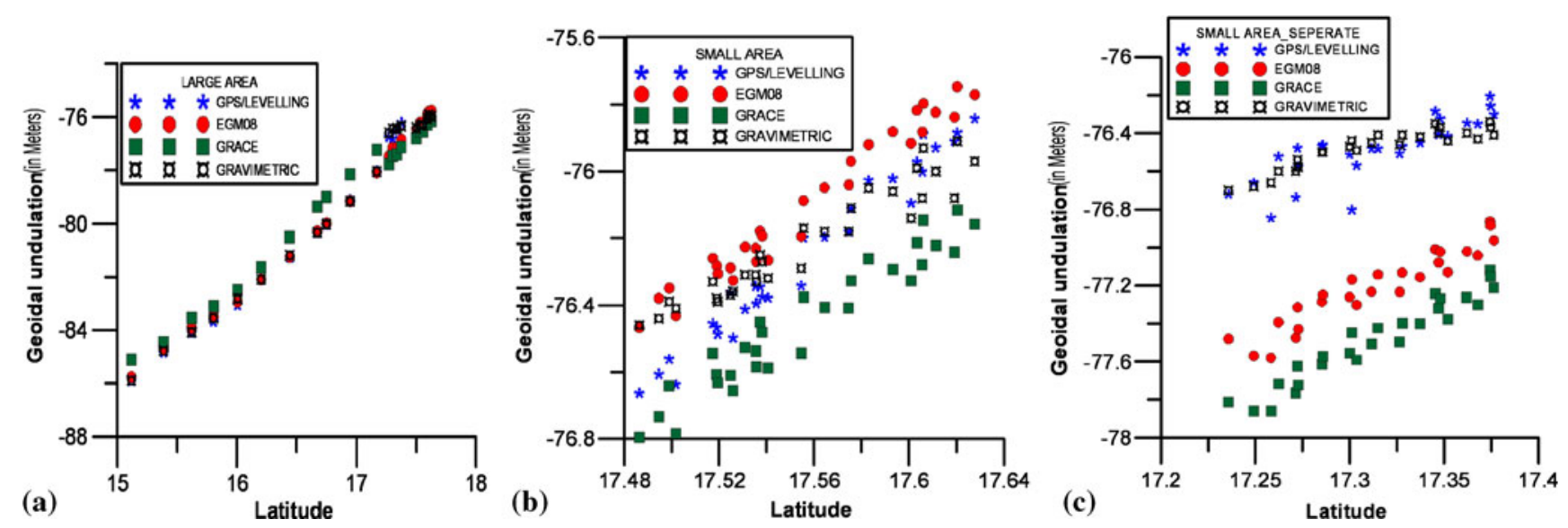

Figure 5. (a), (b) and (c) are plots comparing geoid models: EGM2008, EIGEN-GRACE02S and gravimetric geoid with GPS-levelling, respectively for regions A, B and C.

gravimetric geoid to local level by using the geoid undulation from GPS-levelling $\left(N_{\mathrm{GPS}}\right)$.

$$
N_{\text {Fitted }}=N_{\text {Gravimetric geoid }}+\text { Error }_{\text {Grid }}
$$

\section{Results and comparison}

The present study covers three dissimilar ranges of area; large region extended over $\sim 300 \mathrm{~km}$ between the latitude $12^{\circ} .5^{\prime} \leq \phi \leq 18^{\circ} .5^{\prime}$ and longitude $75^{\circ} .5^{\prime} \leq \lambda \leq 79^{\circ} .5^{\prime}$ and the two small regions having an area of $\sim 30 \mathrm{~km}^{2}$ each. In the large region (region A), 21 BMs from Gooty (Karnataka) to Bhongir (Andhra Pradesh) are occupied with GPS (figure 1). GPS measurements at $56(30+26) \mathrm{BMs}$ positioned in the grid of $5 \mathrm{~km}$ in the two small regions close to Bhongir are made for assessment of gravimetric geoid. EGM2008 and EGM1996 global gravity models are utilized for computation of gravimetric geoid and it has been noted that geoid computed using EGM2008 is better compared to the geoid computed using EGM1996. Thus EGM2008 is used to calculate the local gravimetric geoid. Residual and gravimetric geoids are presented in figure 4( $\mathrm{a}$ and $\mathrm{b})$. The residual geoid is primarily reflecting the subsurface density anomaly. For example, about a one meter of positive residual anomaly observed in the southwestern part of Cuddapah basin might be caused due to a high density crustal materials reported earlier (Mishra and Tiwari 1995). Figures 4(b) and 5(a) show a large wavelength geoidal anomaly decreasing towards south, generally known as Indian Ocean Geoidal Low. The cause of this anomaly is attributed to the depression in the Core-Mantle boundary, relict of earlier subduction and so on (Yoshida and Nakakuki 2009). All the studies of this long wave- length geoidal low suggest a deep causative source, a density heterogeneities in the mantle.

The accuracy of the computed gravimetric geoid is estimated using GPS measurements at BMs by simple difference. Difference of gravimetric geoid and the GPS-levelling geoid height at the same observational point has the standard deviation of $0.09 \mathrm{~m}$ which shows the accuracy of gravimetric geoid. This is comparatively better as compared to the standard deviation of differences found from two models referred earlier (table 1). The validation among gravimetric geoid and global geopotential models from the region A (21 points), B (30 points) and $\mathrm{C}$ (26 points) with GPS-levelling geoid $\left(N_{\mathrm{GPS}}\right)$ are tabulated in table 2. From careful examination of differences from different models and GPS data for three regions, it appears $N_{\text {(Gravimetric geoid) }}$ and $N_{\text {EGM2008 }}$ are very close to $N_{\text {(GPS-levelling geoid) }}$ as compared to $N_{\text {(EIGEN-GRACE02S) }}$ in the regions A (figure $5 \mathrm{a}$ ) and $\mathrm{B}$ (figure $5 \mathrm{~b}$ ). But in the case of region $\mathrm{C}$, only $N_{\text {(Gravimetric geoid) }}$ is close to $N_{\text {(GPS-levelling geoid) }}$. Mismatch with EGM2008 (figure 5c), might have aroused due to lack of terrestrial data over small region. Such examples are reported from other places as well (Benahmed 2010; Corchete 2010). The mismatch with global geoid models might also

Table 1. Statistical comparison of gravimetric geoid model and GGMs with GPS-levelling geoid in benchmarks.

\begin{tabular}{lccccc}
\hline Geoid model & Points & $\begin{array}{c}\text { S.D. } \\
(\mathrm{m})\end{array}$ & $\begin{array}{c}\text { Mean } \\
(\mathrm{m})\end{array}$ & $\begin{array}{c}\text { Maxi } \\
(\mathrm{m})\end{array}$ & $\begin{array}{c}\text { Min } \\
(\mathrm{m})\end{array}$ \\
\hline EGM2008 & 67 & 0.42 & 0.20 & 0.91 & -0.22 \\
EIGEN-GRACE02S & 67 & 0.61 & 0.35 & 1.19 & -1.04 \\
Gravimetric & 67 & 0.09 & -0.02 & 0.17 & -0.36 \\
\hline
\end{tabular}


Table 2. Comparison of geoid undulation (N) accuracy with respect to geoids model in three dissimilar regions.

\begin{tabular}{lccc}
\hline $\begin{array}{l}\text { Region } \\
\text { (no. of points) }\end{array}$ & $\begin{array}{c}\text { EGM2008 } \\
\text { rms }(\mathrm{m})\end{array}$ & $\begin{array}{c}\text { EIGEN-GRACE02S } \\
\text { rms }(\mathrm{m})\end{array}$ & $\begin{array}{c}\text { Gravimetric } \\
\text { rms }(\mathrm{m})\end{array}$ \\
\hline A (21 points) & 0.29 & 0.67 & 0.12 \\
B (30 points) & 0.15 & 0.2 & 0.1 \\
C (26 points) & 0.73 & 1 & 0.1 \\
\hline
\end{tabular}
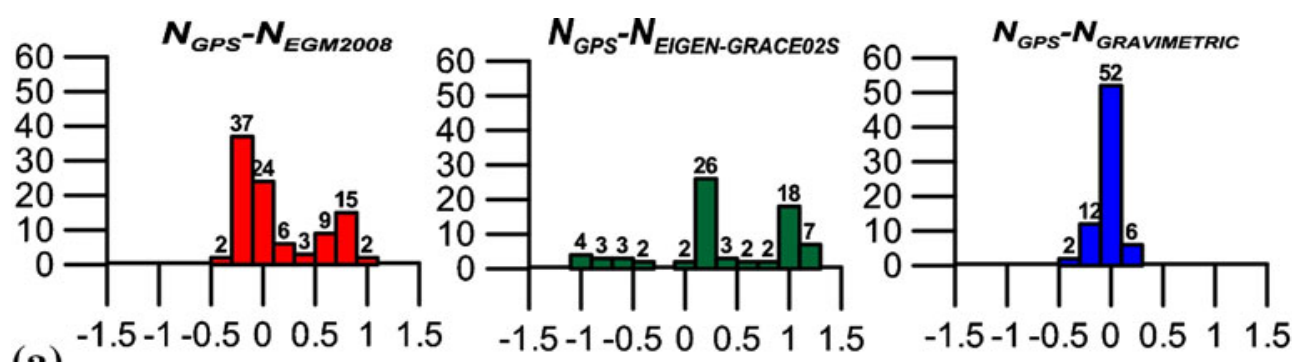

(a)

$-1.5-1-0.500 .5 \quad 1 \quad 1.5$
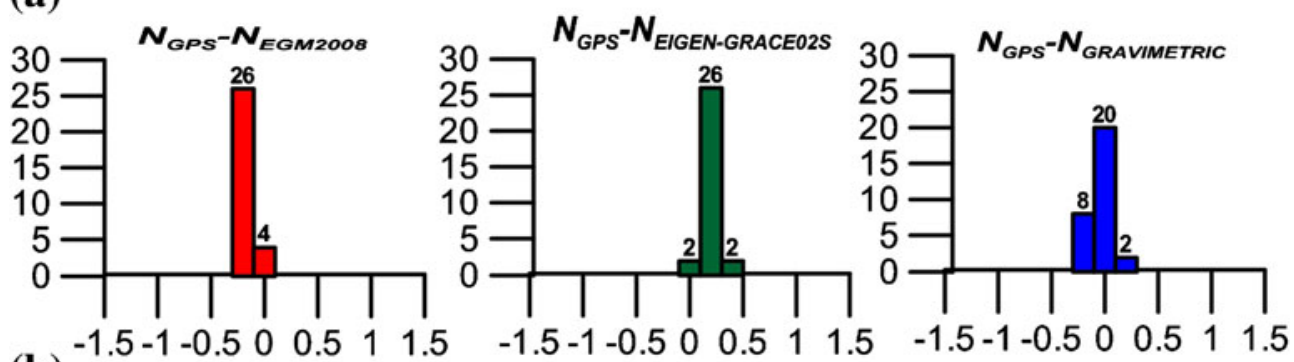

(b)
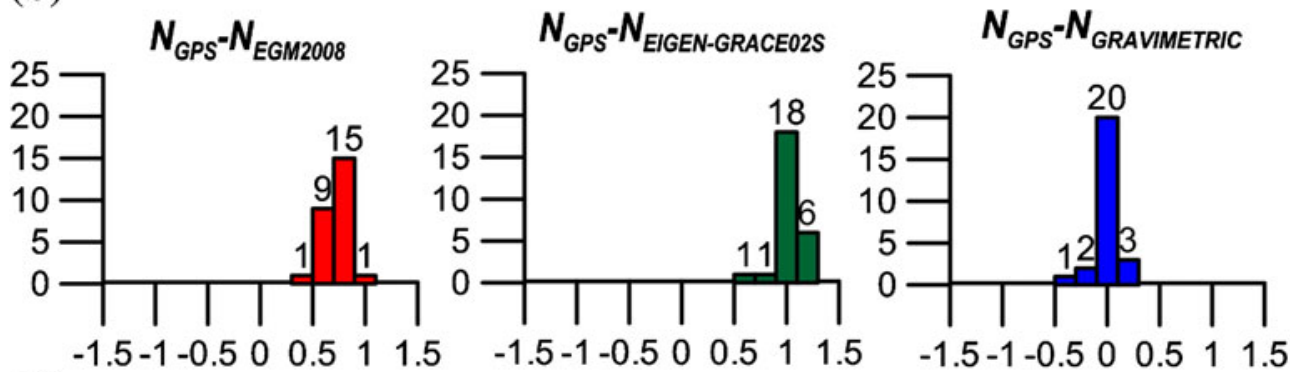

(c)

Figure 6. (a), (b) and (c) Histograms of the differences of $N_{\text {GPS-levelling geoid }}-N_{\text {EGM2008 }}, N_{\text {GPS-levelling geoid }}-$ $N_{\text {EIGEN-GRACE02S }}$ and $N_{\text {GPS-levelling geoid }}-N_{\text {Gravimetric }}$ for regions A, B and C.

arise due to the fact that their spatial resolution is limited. The EIGEN-GRACE02S gravity model is derived solely from GRACE satellite data and reported to have $1 \mathrm{~cm}$ accuracy of geoid model with a spectral resolution up to degree and order 150 (Reigber et al. 2005). From statistics of the differences in benchmarks between EIGEN-GRACE02S geoid model and the GPS-levelling derived geoid height shows the standard deviation and mean of about 0.61 and $0.35 \mathrm{~m}$, respectively. Similarly, the standard deviation and mean of differences in EGM2008 geoid model and the GPS-levelling geoid height are 0.42 and $0.20 \mathrm{~m}$, respectively. The EGM2008 (Pavlis et al. 2008), provides spherical harmonic expansion up to degree 2190 and order 2159 to compute geoid at any place.

\section{Conclusions}

Geoid undulations over a part of southern Indian region are computed from terrestrial gravity data, which allowed investigating the comparison of gravimetric geoid with geoids from global geopotential model and GPS-levelling data. At first glance, an agreement between GPS-levelling data and global geopotential model is found on regional scale (figure 6a and b). However, over small region 
(figure 6c), geoid from GPS-levelling is considerably different (in meter). Therefore, it is necessary to compute gravimetric geoid from terrestrial data to achieve orthometric height in $\mathrm{cm}$ accuracy using GPS. Results of present exercise can be viewed as follows.

- EGM2008 can provide a transformation platform from ellipsoid to local datum. RMS difference of $0.46 \mathrm{~m}$ is observed between EGM2008 and GPS-levelling data and therefore, EGM2008 can be used in most of the surveys for geophysical applications. Nevertheless, a mismatch up to an order of one meter restricts its use in engineering applications.

- Computation of local gravimetric geoid using existing gravity data from GMSI 2006 and elevation data from GTOPO30 can provide geoidal undulations that can be used to achieve orthometric height to the accuracy of about $10 \mathrm{~cm}$ (RMS $0.01 \mathrm{~m}$ ).

\section{Acknowledgements}

The authors would like to thank the Director, NGRI for his support and permission to publish this work. They are also thankful to C C Tscherning, for sharing GRAVSOFT and to Vagner Gonçalves for fruitful discussions. IFCPAR is acknowledged for the financial support provided through a project on Hydrology and Water Resources from Space over Indian region at NGRI.

\section{References}

Benahmed D S A 2010 Precision assessment of the orthometric heights determination in northern part of Algeria by combining the GPS data and the local geoid model; Compt. Rendus Geosci. 342 87-94.

Corchete V 2010 The high-resolution gravimetric geoid of Italy: ITG2009; J. African Earth Sci. 58 580-584.

De lacy M C, Caderot G R, Marin E, Ruiz A, Borque M J, Gil A J and Biagi L 2001 A gravimetric geoid computation and comparison with GPS results in northern andalusia (spain); Studia Geophys. Geod. 45 55-66.

Forsberg R 1992 Modelling the fine-structure of the geoid: Methods, data requirements and some results; Surv. Geophys. 14 403-418.

Forsberg R 1994 Terrain effects in Geoid computations; Lecture notes, School for the Determination and Use of Geoid, Milano.
Forsberg R and Tscherning C C 1981 The use of height data in gravity field approximation by collocation; J. Geophys. Res. 86 7843-7854.

Gravity Map of Series of India (GMSI) 2006 Gravity anomaly maps of India on 1:2 million scale published by Geological Survey of India; GSI, Hyderabad, India.

Heiskanen W A and Moritz H 1967 Physical geodesy; W H Freeman, San Francisco.

Knudsen P 1987 Estimation and modelling of the local empirical covariance function using gravity data and satellite altimeter data; J. Geophys. Res. 86 78437854 .

Luo Z C and Chen Y Q 2002 Precise determination of Hong Kong geoid using heterogeneous data; FIG XXII International Congress, Washington D.C., USA.

Marsh J G 1979 Satellite derived gravity maps; In: A geophysical atlas for interpretation of satellite derived data, Section 2 (eds) Lowman P D and Fray H V, NASA, Greenbelt, USA.

Mishra D C and Tiwari V M 1995 An asymmetric basic lopolith below sediments in western Cuddapah basin geophysical evidence; Proceedings of the Geological Society of India; annual convention and seminar on 'Cuddapah basin', Tirupati, India, pp. 31-41.

Pavlis N K, Holmes S A, Kenyon S C and Factor J K 2008 An earth gravitational model to degree 2160: EGM2008; General Assembly of the European Geosciences Union, Vienna, Austria.

Reigber C, Schmidt R, Flechtner F, König R, Meyer U, Neumayer K H, Schwintzer P and Zhu S Y 2005 Earth gravity field model complete to degree and order 150 from GRACE: EIGEN-GRACE02S; J. Geodyn. 39(1) $1-10$.

Singh S K, Nagarajan B and Garg P K 2007 Determination of local gravimetric geoid; Coordinates 3 14-19.

Sterzai P, Coren F, Creati N, Marson N and Maso M 2008 An improved geoid in north eastern Italy; Observing our Changing Earth International Association of Geodesy Symposia 133(2) 427-430.

Tarial J S 2010 Determination of precise geoid from terrestrial gravity field and its comparison with geoid from grace satellite gravity mission and global geopotential model; Project Report, Indian Institute of Survey and Mapping, Hyderabad, India.

Tscherning C C 2008 Geoid determination by 3D leastsquares collocation; Draft version.

Tscherning C C, Forsberg R and Knudsen P 1992 Description of the GRAVSOFT package for geoid determination; Proceedings of First Continental Workshop on the Geoid in Europe, Prague, pp. 327-334.

Yilmaz I, Yilmaz M, Gullu M and Turgut B 2010 Evaluation of recent global geopotential models based on GPSlevelling data over Afyonkarahisar (Turkey); Sci. Res. Essays 5(5) 484-493.

Yoshida M and Nakakuki T 2009 Effects on the longwavelength geoid anomaly of lateral viscosity variations caused by stiff subducting slabs, weak plate margins and lower mantle rheology; Phys. Earth Planet. Int. 172 $278-288$. 